\title{
The differential induction machine: Theory and performance
}

\author{
SUMITA SINHA* ${ }^{*}$ NIRMAL K DEB ${ }^{* *}$, NIKHIL MONDAL ${ }^{* *}$ and \\ SUJIT K BISWAS**
}

*Department of Electrical Engineering, Central Calcutta Polytechnic, Kolkata 700014

** Department of Electrical Engineering, Jadavpur University, Kolkata 700032 e-mail: ccp_sumitasinha@rediffmail.com; nkdeb@ee.jdvu.ac.in; nikhilmondal_ju@yahoo.com; sujit_biswas@hotmail.com

\begin{abstract}
This paper presents the theory and performance of a differential induction machine, which is a special type of induction machine having two shafts projected from the two ends of a single stator. Application of a differential load on the two shafts cause them to run at different speed as a motor, which permits true differential movement and thus can meet the requirements of a differential drive in an electric vehicle. The machine is also capable of regeneration in the differential mode. This paper presents the construction of the above machine and performance of the same based on experimental results from a laboratory prototype. The equivalent circuit of the motor has been presented and verified experimentally.
\end{abstract}

Keywords. Differential drive; electric vehicle drive; induction machine.

\section{Introduction}

The concept of a differential motor was presented (Crelerot et al 1993), but was never analysed in detail nor verified experimentally. This paper presents the theory, construction and performance of the machine, based on experimental results from a laboratory prototype. The equivalent circuit of the machine has been developed with the two rotors equivalence in series but shows a non-linear parameter content, which was never reported earlier. This has been verified for both motor and generator mode of operation. The results show that the machine is well suited as a motor for differential drive for an electric vehicle.

In an electric vehicle, whenever the vehicle is needed to make a turn, the wheel on the inner side makes fewer revolutions than the wheel on the outer side in order to create rotation of the shaft connecting the two wheels and hence turn the vehicle. The difference in speed is dependant on the radius of curvature of the turn being taken by the vehicle and the spacing between the two wheels. This is possible in conventional vehicles through the use of a differential gear system that connects the two wheels (on opposite sides of the electric vehicle) on the same shaft to the single prime-mover. However, with the differential induction machine, the two shafts can be directly connected to the two co-axial wheels on opposite sides of the electric vehicle, making it possible to provide driving power along with the 


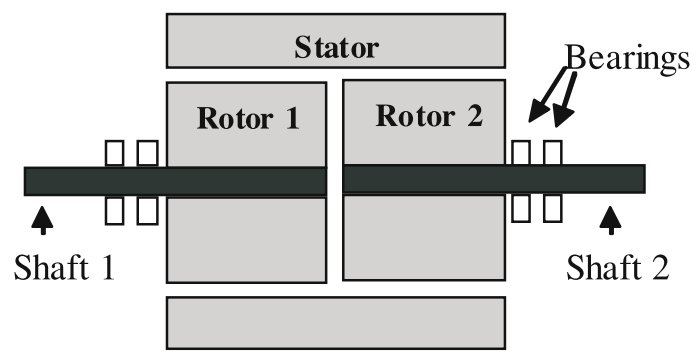

Figure 1. Schematic diagram of the machine.

feasibility of taking a turn. Further, whenever the vehicle is coming down a gradient with sufficient speed, the braking torque can be converted into sufficient electrical energy to partially charge back the energy storage battery (that otherwise supplies energy for driving the vehicle).

\section{Construction}

The differential induction machine has two mechanically separated rotors inside a common stator, as shown in figure 1. The two rotors are identical and of squirrel cage type, axially separated from each other. The length of iron part of one rotor is about half of the stator length. Each rotor shaft is fixed by two bearing at driving end only since internal bearings will become heated by eddy currents due to flux. Thus the axial gap between the two rotors is also at minimum. The stator has a 4 pole, 3 phase balanced winding. The rotor has higher leakage inductance than a normal machine due to the separating gap between the two rotors under the common stator. This causes reduction in torque, which is compensated by designing the rotors as double cage construction.

\section{Equivalent circuit}

The equivalent circuit of the motor as shown in figure 2 , is similar to that of a conventional induction motor, but with two rotors in series. The parameters of the equivalent circuit as obtained from test results show that magnetizing reactances and core loss component resistances change due to the tendency of one core to saturate when one rotor is loaded more than the other. Flux of the two rotors, when run at different load, changes



Figure 2. Equivalent circuit of the machine (per phase). 


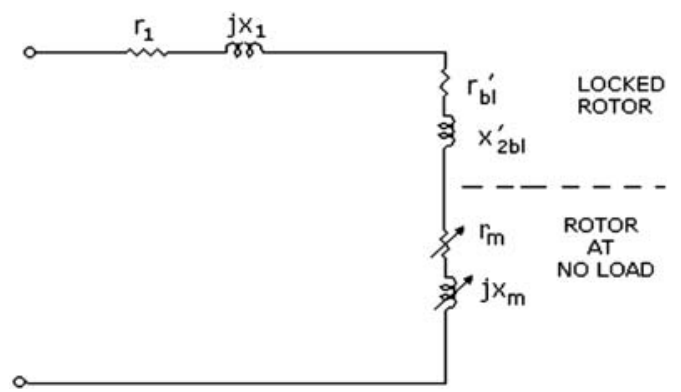

Figure 3. Equivalent circuit with one rotor locked and other at no-load.

accordingly and is dependent on slip of rotor $1\left(s_{1}\right)$ and rotor $2\left(s_{2}\right)$. The rotor with lighter load has higher flux. Both rotors are subjected to different load condition and in extreme case, when one rotor is locked and the other at no-load condition, the input current drawn is somewhat higher than the rated current and not several times higher (as in conventional machine). However, when both rotors are locked, it behaves as a normal induction motor.

When one rotor is locked and the other rotor is at no load as shown in figure 3, the difference in slip between the rotors is maximum and voltage across the light running rotor becomes about 1.3 times than that at no load condition, with rated current. Thus rotor at no load enters saturation and its value of $x_{m}$ and $r_{m}$ are reduced to justify the increased core loss. Hence, in contrast to conventional equivalent circuits, the equivalent circuit for this machine is proposed with variable values of $x_{m}$ and $r_{m}$, as presented in figure 2. This aspect is not reported in existing literature pertaining to this machine.

From no-load and blocked rotors test data (both rotors blocked) assuming $x_{1}: x_{21 s}: x_{22 S}=$ 1:0.4:0.4 and taking no-load rotational loss as $30 \mathrm{watt} /$ phase (from experimental data), the following parameters of the motor are obtained:

$$
\begin{aligned}
& r_{1}=0.187 \mathrm{ohms} \\
& r_{2}^{\prime}=0.172 \mathrm{ohms} \\
& x_{2 S}^{\prime}=0.23 \mathrm{ohms} \\
& r_{m}=0.694 \mathrm{ohms} \\
& x_{m}=5.064 \mathrm{ohms}
\end{aligned}
$$

The value of $r_{m}$ and $x_{m}$ as obtained from test data are as follows.

$$
\begin{array}{lll}
\text { Unsaturated } & r_{m}=0.694 \mathrm{ohms} ; & x_{m}=5.064 \mathrm{ohms} \\
\text { Saturated } & r_{m}=0.311 \mathrm{ohms} ; & x_{m}=3.0 \mathrm{ohms} .
\end{array}
$$

Since the rotor is double-cage, the parameters will change from standstill to full-speed condition (Alger 1951). The motor parameters considered are given below:

$$
\begin{array}{lll}
\multicolumn{2}{l}{\text { Standstill condition }} & \text { Running condition } \\
r_{2}^{\prime} & 0.172 \mathrm{ohms} & 0.0755 \mathrm{ohms} \\
x_{2 S}^{\prime} & 0.23 \mathrm{ohms} & 0.281 \mathrm{ohms} .
\end{array}
$$

Note that at no-load for the above values are not needed since the rotor circuit will be open. 
Table 1. Comparison of experimental data with calculated values.

\begin{tabular}{|c|c|c|c|c|c|c|c|c|}
\hline \multirow{2}{*}{$\begin{array}{l}\text { Set } \\
\text { No. }\end{array}$} & \multirow{2}{*}{$\begin{array}{c}\text { Stator } \\
\text { amperes } \\
\text { (expt) }\end{array}$} & \multirow{2}{*}{$\begin{array}{c}\text { Stator } \\
\text { amperes } \\
\text { (calculated) }\end{array}$} & \multirow{2}{*}{$\begin{array}{l}\text { Power } \\
\text { factor } \\
\text { (expt) }\end{array}$} & \multirow{2}{*}{$\begin{array}{c}\text { Power } \\
\text { factor } \\
\text { (calculated) }\end{array}$} & \multirow{2}{*}{$\begin{array}{l}\text { Input } \\
\text { power } \\
\text { in watts } \\
\text { (expt) }\end{array}$} & \multirow{2}{*}{$\begin{array}{c}\text { Input } \\
\text { power } \\
\text { in watts } \\
\text { (calculated) }\end{array}$} & \multicolumn{2}{|c|}{ Rotor slip (expt) } \\
\hline & & & & & & & $s_{1}(\mathrm{pu})$ & $s_{2}(\mathrm{pu})$ \\
\hline$x$ & 10 . & 10 & 0 & 0.2 & 24 & $2 ?$ & $0 \cdot 0$ & $0 \cdot 0$ \\
\hline 2 & $10 \cdot 8$ & $10 \cdot 6$ & $0 \cdot 302$ & $0 \cdot 31$ & 352 & 361.9 & 0.003 & 0.003 \\
\hline 3 & 17 & $16 \cdot 4$ & 0.65 & 0.65 & 1270 & 1204 & 0.008 & 0.03 \\
\hline 4 & 12 & 11 & $-0 \cdot 166$ & $-0 \cdot 163$ & -230 & -236 & -0.00006 & -0.011 \\
\hline
\end{tabular}

\section{Verification of equivalent circuit}

In order to verify the equivalent circuit, a set of experiments was carried out at different conditions of loading, including differential and balanced loadings. Using the experimental value of slip, calculation was performed with the equivalent circuit parameters obtained earlier to predict the performance data. The calculated values are depicted adjacent to the experimentally obtained values in table 1 . The two sets of data are observed to be numerically close, confirming the validity of the proposed equivalent circuit.

Data set No. 1 of table 1 depicts the condition when both rotors run at no-load in motoring mode. Set No. 2 shows the situation when both rotors are equally loaded as motor, while set No. 3 shows the situation for unequal loading and set No. 4 depicts the condition when both rotors run at more than synchronous speed (generator mode).

\section{Performance}

Different performance characteristics of the differential machine as a motor are shown in the following figures. The three sets of data depicted in the form of three curves (a), (b) and (c), correspond to:

a) One rotor is maintained at no-load while the other is loaded as a motor.

b) Both rotors are equally loaded as motor.

c) One rotor is loaded to a fixed high value of slip as motor, while the load on the other rotor is varied.

Figure 4 depicts the torque versus slip characteristics under the different conditions stated. The set of data clearly shows that the torque-slip characteristic of one shaft is dependent on the loading of the other-a unique feature that makes the machine suitable as a differential drive.

Figure 5 represents the power input as a motor versus the input current for the three specified conditions. Note that the power deliverable from one shaft is restricted when the other shaft is at no-load. Similarly, when one shaft is heavily loaded, the power output from the other shaft is restricted.

Figure 6 represents the input power factor versus the input current as a motor for the three specified conditions. The input power factor is poor when only one shaft is loaded and the other is at no-load. Power factor increases for the same input current when load is increased on the other shaft. 


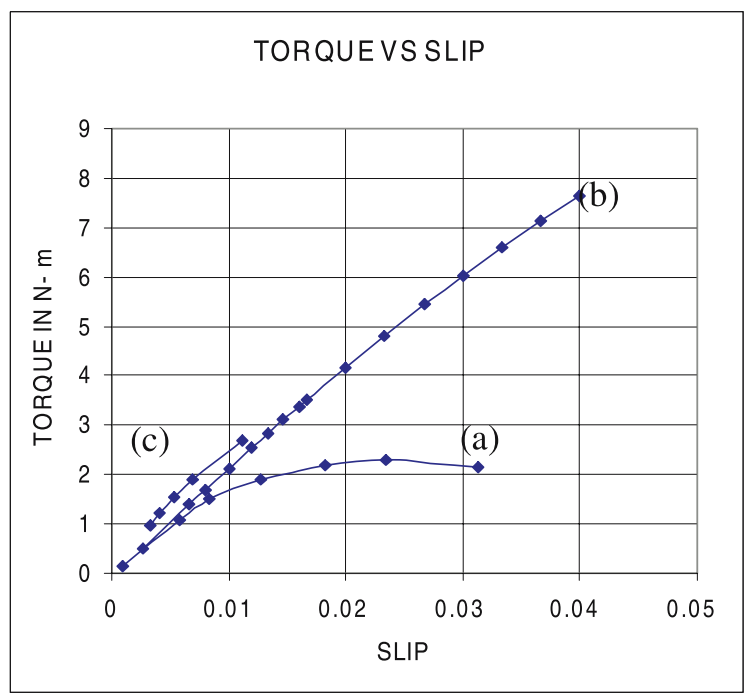

Figure 4. Torque in N-m Vs. Slip.

Figure 7 represents the efficiency as a motor versus the input current for the three specified conditions. As in the earlier results, the efficiency is best for balanced operation of the two shafts.

Figure 8 presents the torque versus slip curves of both rotors as the slip is changed in a particular manner. The slip of rotor 1 is intentionally held constant (by suitable load variation) while the slip of rotor 2 is increased in steps. From these curves, it is clear that torque in rotor 1 and rotor 2 both changes due to change in slip of rotor 2, even when slip of rotor 1 remains constant. This is a special feature of the differential induction machine, making it suitable for driving an electric vehicle in differential mode.

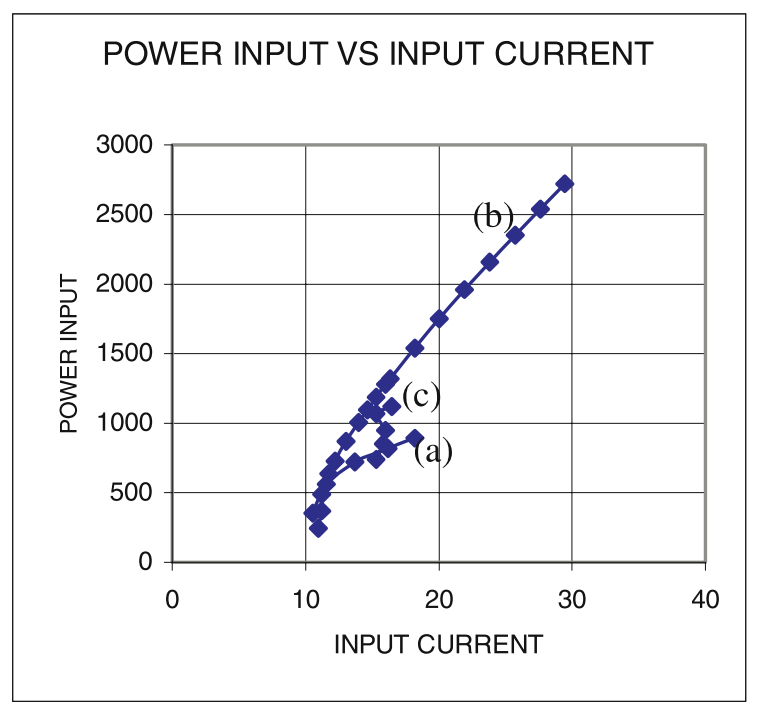

Figure 5. Power input in watt Vs input current in amperes. 


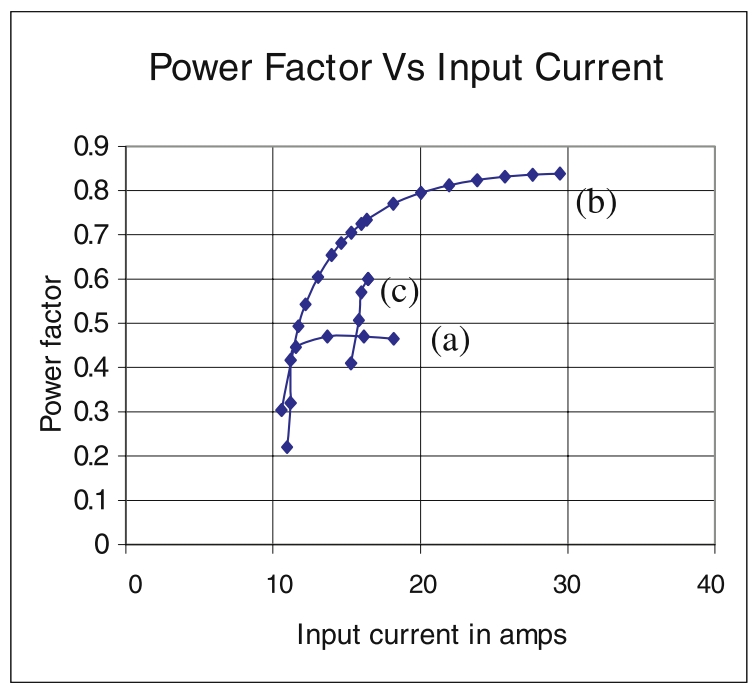

Figure 6. Power factor Vs. input current in amps.

\section{Generator mode of operation}

Any motor applied to an electric vehicle is likely to be subjected to regeneration during deceleration and braking, apart from when going down-hill. The machine was thus tested by running it as a generator by driving it from both its shafts at the same time, at supersynchronous speeds. The two driving sources were intentionally made to operate at different speeds so that two different values of slip were obtained, each being negative. The machine successfully operated as an induction generator and power was fed back through its common stator terminals to the ac supply. Performance characteristics of the differential machine as a

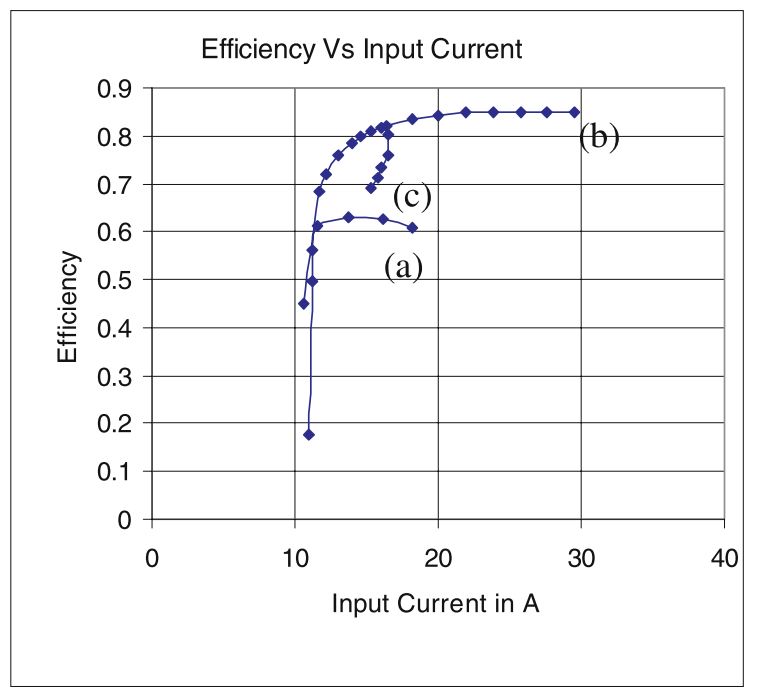

Figure 7. Efficiencies Vs input current in amps. 


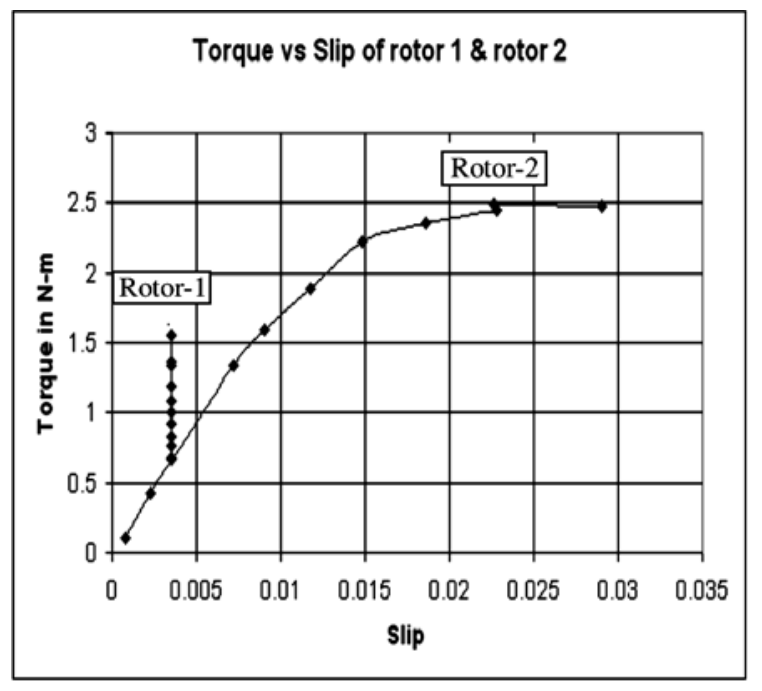

Figure 8. Torque in $\mathrm{N}-\mathrm{m}$ of both rotors Vs slip.

generator, are shown in figures 9 and 10 . The three sets of data depicted in the form of three curves (x), (y) and (z), correspond to:

$\mathrm{x})$ One rotor is maintained at low value negative slip while the negative slip of the other is increased.

y) One rotor is maintained at significant value of negative slip, while the negative slip on the other rotor is varied.

z) Both rotors are at equal negative slip which is varied together.

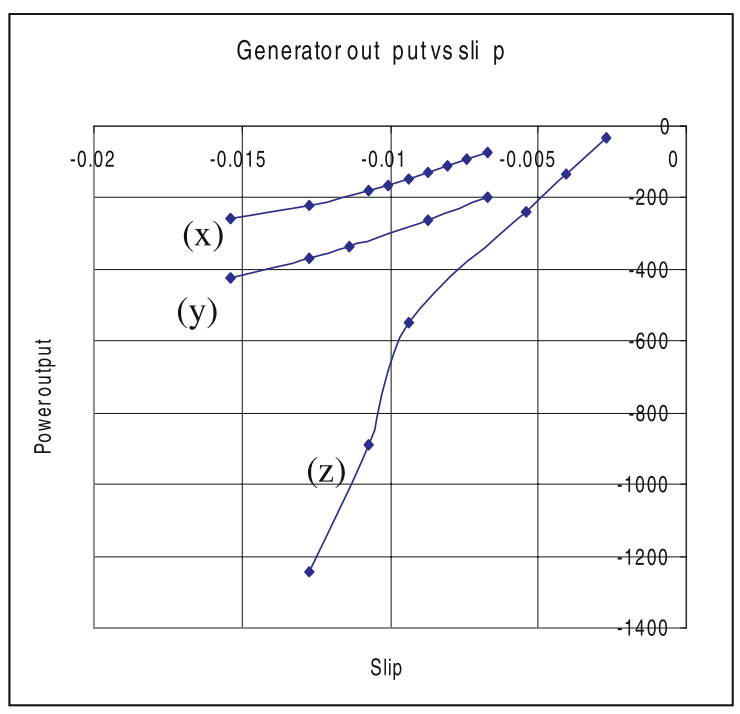

Figure 9. Generator output in watt Vs. slip. 


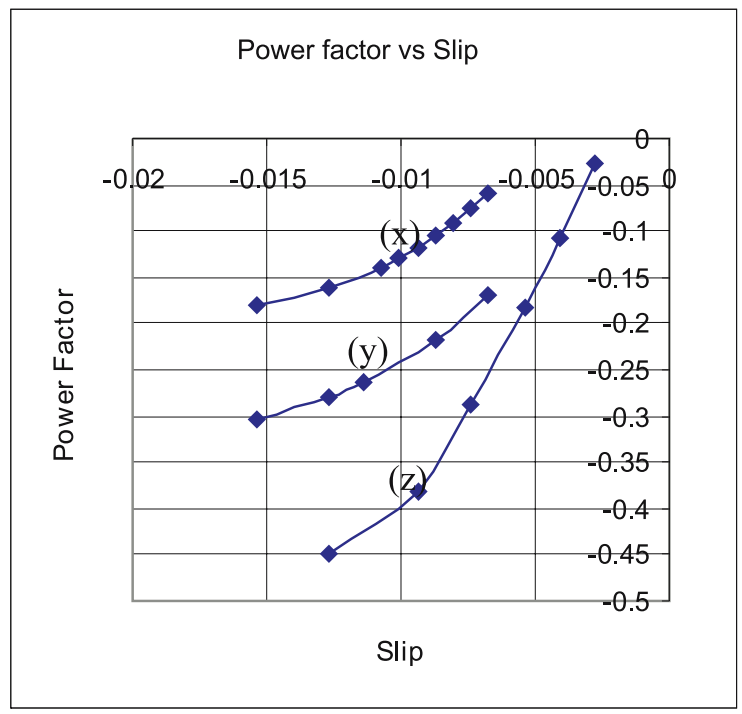

Figure 10. Generator output power factor Vs. slip.

Figure 9 represents the power output as a generator versus the slip of one rotor for the three above specified conditions. Note that the power deliverable from one rotor is proportional to slip as in conventional induction generator, but is also dependent on the slip of the other rotor in this case.

Figure 10 represents the output power factor versus the slip of one rotor as a generator for the three above specified conditions. Note that the Differential Induction Machine draws lagging reactive power as in conventional induction generator and the pf depends on the slip of both the rotors.

\section{Conclusion}

The operation and performance of an induction machine with two rotors, operating as a differential drive, has been demonstrated in this paper. The equivalent circuit proposed has non-linear elements, but has been verified through test data as motor as well as generator at different conditions. The operating characteristics of the machine as a motor as well as a generator have been demonstrated with different speed on the two shafts. The results show that the machine is well suited for use in electric vehicles as the direct drives for two opposite wheels with differential capabilities.

\section{References}

Alger P L 1951 The Nature of Polyphase Induction Machine. (New York: J. Wiley \& Sons)

Crelerot O, Bernot F, Kauffmann J F 1993 Study of an electrical differential motor for electrical car. IEE Conference Publication no. 376 8-10 